\title{
PERCEPÇÃO DE PROFESSORES DO SISTEMA DE ENSINO DO ESTADO DE SÃO PAULO SOBRE SEU PREPARO EM SAÚDE DO ESCOLAR*
}

\author{
Edméa Rita Temporini**
}

\begin{abstract}
TEMPORINI, E.R. Percepção de professores do Sistema de Ensino do Estado de São Paulo sobre o seu preparo em saúde do escolar. Rev. Saúde públ., S. Paulo, 22:411-21, 1988.

RESUMO: Apresenta-se estudo sobre o preparo de professores para realizarem açōes que visam à identificação e atendimento de escolares com problemas de saúde. Pretendeu-se oferecer subsídios para o planejamento de programas de treinamento de docentes aos setores governamentais interessados na temática. A população foi constituída por 532 professores da primeira série do primeiro grau, de escolas estaduais situadas em treze municipios do Estado de São Paulo, Brasil, onde inicialmente foi implantado o "Sistema Integrado de Atendimento Médico ao Escolar". Utilizou-se questionário como instrumento de medida. Os resultados revelaram que $74,3 \%$ dos professores se consideraram atingidos pela orientação sobre observação de saúde e medidas para solucionar desvios de saúde. A cobertura na orientação transmitida pelos orientadores de açð̃es de assistência ao escolar (OAE) variou, entre os municípios, nos limites de 70 a $100 \%$. A relação entre o fato de o professor ter recebido explicaçðes do OAE e o melhor grau na auto-avaliação de preparo, indica, provavelmente, eficácia do trabalho do OAE. Recomenda-se incremento de orientação na rede estadual de ensino, ampliando os conhecimentos sobre saúde e a compreensão do professor a respeito de sua participação em programas de saúde escolar.
\end{abstract}

UNITERMOS: Saúde escolar. Serviços de saúde escolar. Treinamento em serviço. Professores.

\section{INTRODUÇÃO}

O presente trabalho versa sobre o preparo de professores de primeira série do primeiro grau, de escolas estaduais, para realizarem ações que visam à identificação e atendimento de alunos portadores de desvios de saúde.

É inegável que a criança em idade escolar encontra-se sujeita a morbidades e agravos decorrentes de fatores pessoais e ambientais, com possível repercussão na aprendizagem ${ }^{21,24,25}$.

Por vezes, tais desvios passam despercebidos por não existir um trabalho sistematizado de detecção e seguimento de casos, o que requer ação coordenada entre profissionais de saúde, mestres e pais ${ }^{6,19,22}$.

Muitos desses distúrbios podem manifestar-se por meio de sinais e comportamentos, observáveis por pessoas devidamente preparadas que lidam diariamente com a criança como, por exemplo, o professor de classe.

Especialistas em saúde escolar são unânimes quanto à propriedade de o professor observar o estado de saúde dos alunos, salientando a posição estratégica do mestre para desempenhar es- sa tarefa devido ao seu contato diário e prolongado com os estudantes. Tal convivência lhe propicia vantagem incomum para conhecer $o$ modo de ser de cada um deles e notar mudanças na aparência ou na conduta, que podem ser prenúncio de defeitos ou enfermidades ${ }^{1,11,12,13,23}$.

Embora a instituição educacional não tenha a tarefa precípua de dar atendimento a problemas de saúde dos alunos, existe uma obrigação inerente à profissão de ensinar, no sentido de promover o bem-estar das crianças e criar melhores condiçðes para a sua aprendizagem 1 .

Contudo, já se evidenciou que o mestre nem sempre dispõe de conhecimentos, atitudes, habilidades e práticas no campo da saúde escolar que, supostamente, deveriam ter sido adquiridos no curso de formação do magistério $2,5,7,8,17$.

A fim de suprir, em parte, essa lacuna, o Departamento de Assistência ao Escolar (DAE)***, órgão do Governo do Estado de São Paulo, vinha executando programa de orientação em saúde, com vistas a capacitar o professor a agir face a desvios de saúde de seus alunos ${ }^{15}$.

\footnotetext{
* Baseado na Tese de Doutorado, intitulada "Saúde do Escolar-Conduta e Opinião de Professores do Sistema de Ensino do Estado de São Paulo", apresentada à Faculdade de Saúde Pública da Universidade de São Paulo, em 1986.

* Departamento de Prática de Saúde Pública da Faculdade de Saúde Pública da Universidade de São Paulo - Av. Dr. Arnaldo, 715 - 01255 - São Paulo, SP - Brasil.

*** Transferido da Secretaria da Educação para a Secretaria da Saúde mediante o Decreto n: 26.962, de 22 de abril de 1987.
} 
Para ampliar a cobertura de orientação a pessoal docente e discente, foi instituído no sistema estadual de ensino o orientador de ações de assistência ao escolar (OAE), denominação conferida ao professor que se encarregava da multiplicação das orientações em saúde a nível de unidade escolar ${ }^{4}$.

Esses multiplicadores recebiam treinamento específico no decorrer do ano, mediante reuniōes mensais de nível regional, sob responsabilidade de educadores de saúde pública ${ }^{16}$. O conteúdo técnico abordado inicialmente referia-se à participação do professor na avaliação de saúde do escolar e na solução de casos. Assim, esperava-se que o OAE, previamente preparado, orientasse os demais professores da escola sobre observação do estado de saúde dos alunos, encaminhamento e controle de casos, aplicação do teste de acuidade visual e integração das ações de saúde ao ensino de classe ${ }^{9}$. Manual intitulado "Observação de Saúde do Escolar" ${ }^{10}$ foi elaborado e distribuído a professores da primeira série do primeiro grau, complementando orientação ministrada pelos OAEs.

Por outro lado, a observação de condiçð̃es de saúde do aluno, realizada pelo professor de classe, constituía-se, também, no ponto de partida do "Sistema Integrado de Atendimento Médico ao Escolar" (SIAME) ${ }^{20}$, que vinha sendo implantado, gradativamente, desde 1980, em municípios do Estado de São Paulo. Esse sistema previa açð̃es integradas dos setores saúde e educação com a finalidade de prestação de assistência médica a alunos da rede oficial de ensino, utilizando, ao máximo, os recursos existentes na própria localidade. Para alcançar esse objetivo, fazia-se também necessário preparar o professor para efetuar a triagem e encaminhamento de alunos, mediante orientaçōes específicas a ele transmitidas pelo OAE.

Dessa forma, o orientador constituía-se no elemento-chave do trabalho de identificação $\mathrm{e}$ atendimento de problemas de saúde do escolar, atuando como elo de ligação intersistêmico entre técnicos de saúde e pessoal docente.

Considerando-se o tipo de preparo ministrado a professores e o tempo transcorrido na execução desse programa, fez-se conveniente estudar objetivamente essa realidade, com vistas a possíveis intervenções.

Nesse enfoque, $O$ presente trabalho tem por objeto o estudo das características do preparo de professores da primeira série do primeiro grau do sistema estadual de ensino, para participarem de ações de saúde na escola.

Pretendeu-se, com esta pesquisa, oferecer subsídios para o planejamento de programas de treinamento de docentes, no que respeita à ava- liação e atendimento de problẹmas de saúde do escolar.

\section{METODOLOGIA}

A população do estudo foi composta a partir de alguns critérios referentes a município, unidade escolar e professor, descritos e justificados a seguir.

a) Municipio:

- apresentar no mínimo três anos de participação no SIAME, até 31 de dezembro de 1982, pressupondo a necessidade de haver transcorrido um periodo de experiência com o programa, para se proceder à qualquer observação;

- localizar-se em região administrativa do Estado, cuja respectiva Divisão Regional de Ensino (DRE) contasse com Supervisor Regional de Educação em Saúde do DAE, desde 1980 até a época da coleta de dados, considerando-se aqui o fato de que a ausência desse elemento implicava solução de continuidade nas programações de educação em saúde.

b) Unidade Escolar:

- contar com a atuação de OAE nos períodos letivos de 1980,1981 e 1982, visto ter a experiência mostrado que a ausência desse elemento provocava a interrupção das ações de saúde previstas na escola.

c) Professor:

- lecionar na primeira série do primeiro grau de escola da rede estadual de ensino - esse professor constituía população-alvo prioritária das programações de educação em saúde, tendo em vista diretriz estabelecida pelo DAE, conferindo primazia ao atendimento da criança que ingressa na escola;

- não exercer, cumulativamente, a função de OAE - esse orientador, pelo treinamento especializado que recebia na área de saúde, tornava-se um elemento diferenciado, portanto, sua inclusão na pesquisa provocaria distorção dos resultados.

Atendidos esses critérios, a população de análise foi constituída por 532 professores da primeira série do primeiro grau, distribuídos em 149 unidades escolares da rede estadual de ensino do Estado de São Paulo, participantes, ininterruptamente, durante três anos, no mínimo, do SIAME. Essas escolas situam-se em treze municípios - dois na região da Grande São Paulo e onze nas regiões administrativas do interior do Estado. 
Mediante estudo exploratório e consulta a especialistas elaborou-se um questionário como instrumento de medida, aplicado com o concurso de educadores de saúde pública e dos OAEs que atuavam nas escolas que faziam parte do estudo.

Os dados foram coletados no período de 16 a 24 de junho de 1983 , com a aplicação concomitante do instrumento nas unidades escolares do mesmo município. Esse procedimento teve por finalidade evitar distorçōes nas respostas, decorrentes da possível troca de idéias entre professores da mesma localidade. Cada respondente recebeu um envelope contendo o questionário. Após o preenchimento individual, o professor colocava-o no envelope, fechando-o de maneira inviolável, conforme instruções da etiqueta. Desse modo foram assegurados o anonimato e sigilo dos dados.

Para a apuração dos dados utilizou-se o Sistema SPSS (Statistical Package for the Social Sciences).

Mediu-se a intensidade das possíveis associações entre variáveis utilizando o Coeficiente de Correlação de Kendall, comumente designado por " $T$ " ("Tau"), calculado com correção para assimetria ("Tau-C"), em tabelas onde as variáveis possuíam alguma ordenação ${ }^{18}$.

Aplicou-se também tratamento matemático aos dados obtidos, que consistiu na redução dos valores de uma distribuição a um único valor, denominado Valor Escalar Médio (VEM)*. Atribuíram-se números, com características ponderais, às categorias das escalas ordinais, obtendo-se a média ponderada, ou seja, o valor escalar médio. Esse procedimento tornou possível: 1) situar esse valor dentro de uma escala e, conseqüentemente, ter-se idéia de sua posição ou magnitude relativas; 2) comparar, entre si, os valores de escalas diversas. O processo de atribuição de números foi realizado de acordo com a magnitude presumível do conteúdo implícito em cada categoria.

Como os VEMs são também utilizados para comparar distribuições e como eles são referidos a escalas de amplitudes diferentes, tornou-se necessário padronizar as escalas. Assim, as escalas ordinais foram transformadas de tal modo que seus limites passassem a ser 0 (zero) e 100. Para que o limite superior seja representado pelo número 100 , fez-se necessário multiplicar o VEM pelo resultado da relação entre os limites final e inicial propostos em ambas as escalas.

A apresentação dos resultados por meio do
VEM é feita sem prejuízo da apresentação convencional das distribuiçðes próprias das escalas.

Por ser a resposta do professor o elemento de análise do presente estudo, as tabelas apresentam diferentes totais em decorrência do número variável de respostas obtidas.

\section{RESULTADOS E DISCUSSĀO}

Os resultados foram estruturados de forma descritiva e analítica. As características descritivas constam das Tabelas 1 a 7 e da Figura. As associações entre variáveis são apresentadas nas Tabelas 7 a 10.

Na Tabela 1 encontra-se a população distribuída nos municípios selecionados para o estudo. $\mathrm{O}$ rol apresentado obedece à ordenação dada às respectivas Divisões Regionais de Ensino, na organização administrativa da Secretaria de Estado da Educação.

\section{TABELA 1}

Distribuição de professores da primeira série do primeiro grau de escolas estaduais, nos 13 municípios do Estado de São Paulo selecionados para o estudo. São Paulo, Brasil, 1983

\begin{tabular}{llr}
\hline & \multicolumn{2}{c}{ Professores } \\
\cline { 2 - 3 } Município & $\mathrm{f}$ & $\%$ \\
\hline Arujá & 16 & 3,0 \\
Cotia & 64 & 12,0 \\
Praia Grande & 60 & 11,3 \\
Caçapava & 11 & 2,1 \\
São Roque & 33 & 6,2 \\
Santa Bárbara D'Oeste & 46 & 8,6 \\
Franca & 88 & 16,6 \\
Lençóis Paulista & 11 & 2,1 \\
Catanduva & 42 & 7,9 \\
Presidente Venceslau & 45 & 8,5 \\
Araçatuba & 81 & 15,2 \\
Echaporã & 5 & 0,9 \\
Registro & 30 & 5,6 \\
\hline Total & 532 & 100,0 \\
\hline
\end{tabular}

Na Figura os resultados sofreram uma análise adicional, segundo a qual as subpopulações constituídas pelos professores que receberam e pelos que não receberam o manual "Observação de Saúde do Escolar", foram fragmentadas em termos da leitura total ou parcial. Verifica-se que os resultados referentes aos grupos que leram diferem consoante tenham recebido

* Empregado por A. PIOVESAN - Disciplina Metodologia de Pesquisa em Saúde do Departamento de Prática de Saúde Pública da Faculdade de Saúde Pública da Universidade de São Paulo. 


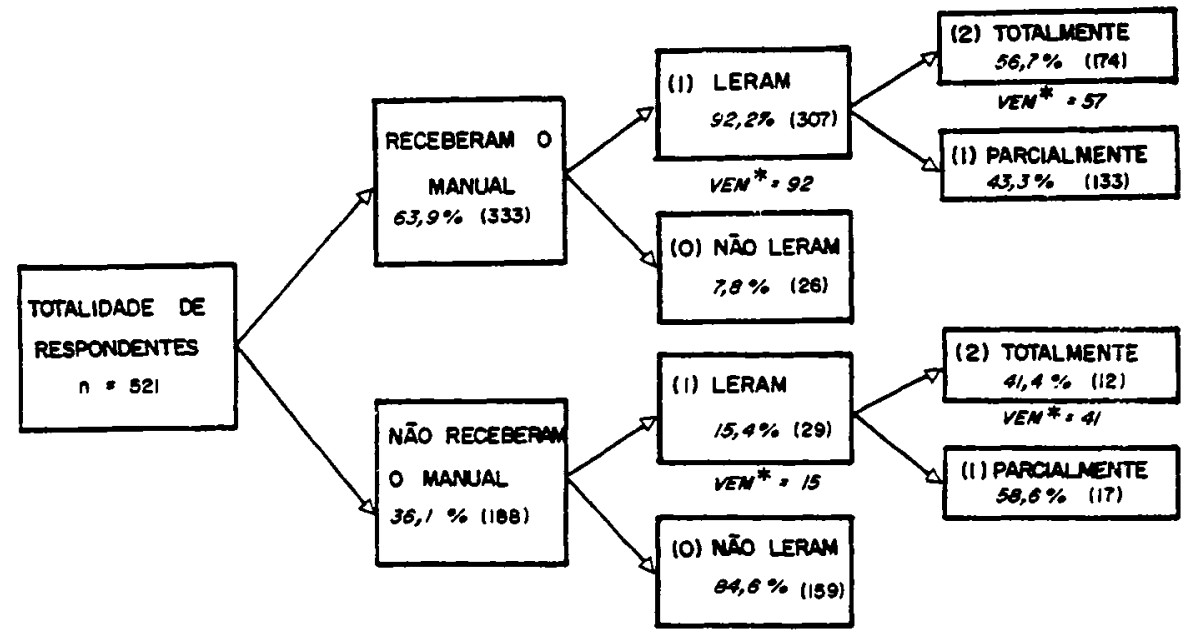

Figura - Recebimento e leitura do Manual "Observação de Saúde do Escolar" pelos professores da primeira série do primeiro grau de escolas estaduais de 13 municípios do Estado de São Paulo, Brasil, 1983.

* $V E M=$ Valor Escalar Médio. Calculađo a partir dos números entre parênteses. Limites da escala: 0 e 100.

ou não o manual. Como se observa, o material foi lido totalmente por $56,7 \%$ dos respondentes que $o$ receberam e leram e apenas por $41,4 \%$ dos que não o receberam mas leram. Portanto, o fato de receber o manual parece influir positivamente, seja na proporção de docentes que o lêem (VEM $=92$ e VEM $=15$ ), seja na extensão com que o material é lido $(\mathrm{VEM}=57 \mathrm{e}$ $\mathrm{VEM}=41$ ).

Do ponto de vista prático, esses dados apresentam particular interesse, em decorrência da ênfase atribuida ao referido manual para o trabalho de orientação aos professores sobre a observação de saúde e atendimento de problemas de saúde do escolar. Como sua distribuição se processa mediante explicações transmitidas pelos OAEs, algumas questőes podem ser colocadas em vista desses resultados. Disporia o OAE de quantidade suficiente de manuais, de que forma estaria utilizando esse subsídio e até que ponto se sentiria seguro para orientar sobre sua aplicação, poderiam ser algumas dessas perguntas. De outro lado, há que se considerar possível solução de continuidade no trabalho do OAE, por licenças ou afastamentos, interferindo na distribuição do manual e respectiva orientação.

A Tabela 2 evidencia os niveis de auto-avaliacão de conhecimentos sobre o conteúdo do referido manual. Esses resultados referem-se somente aos professores que declararam ter lido o manual.

Ao se examinar a Tabela 2, chama a atenção o fato de que $44,3 \%$ dos respondentes se localizam na faixa intermediária dos graus da auto-avaliação de conhecimentos, resultado este não satisfatório do ponto de vista qualitativo. Cumpre ressaltar que este resultado pode estar
TABELA 2

Auto-avaliação de conhecimentos sobre o manual "Observação de Saúde do Escolar". Professores da primeira série do primeiro grau de escolas estaduais de 13 municípios do Estado de São Paulo, Brasil, 1983.

$n=336$

Auto-avaliação de Conhecimentos sobre o manual

(4) Conhece muito bem

(3) Conhece bem

(2) Conhece mais ou menos

(1) Conhece mal

(0) Conhece muito mal

Valor escalar médio*

$2,7(66)$

* Calculado a partir dos números entre parênteses. Limites das escalas: 0 e 4;0 e 100.

relacionado ao fato de ter lido ou não o manual e ter ou não recebido orientação a respeito. Se, de um lado, pode-se questionar a qualidade da orientação ministrada, de outro lado, deve-se levar em conta possiveis obstáculos à realização dessa atividade, destacando-se:

- não recebimento do manual pelo professor - o referido material seria o parâmetro para julgamento quanto a ter ou não recebido explicaçð̃es sobre seu conteúdo;

- entrada de professores novos - se o docente provém de escola e/ou série não atingidas pelo programa, provavelmente não recebeu explicaçס̃es do OAE sobre o manual;

- limitaçðes ao trabalho do OAE, referidas por Mendes e Temporini ${ }^{9}$, tais como, - deficiências no seu preparo em saúde; 
- ausência de motivação, iniciativa ou liderança;

- carga horária insuficiente para o desempenho da função, relativamente ao número de alunos existentes;

- ausência por licenças, afastamentos ou remoção;

- falta de apoio da direção da escola;

- incompatibilidade de seu período de trabalho com o de professores-alvo da orientação, ou do horário de trabalho desses professores entre si.

Nas Tabelas 3 e 4 verifica-se o conteúdo ministrado aos professores pelo orientador, que

\section{TABELA 3}

Programação de educação em saúde: explicações recebidas por meio do orientador de açōes de assistência ao escolar. Professores da primeira série do primeiro grau de escolas estaduais de 13 municípios do Estado de São Paulo, Brasil, 1983.

\begin{tabular}{|c|c|c|c|}
\hline Explicaçōes Recebidas & $n \stackrel{0}{0}$ & f & $\%$ \\
\hline Técnica da observação de saúde & 415 & 393 & 94,7 \\
\hline $\begin{array}{l}\text { Problemas de saúde a serem ob- } \\
\text { servados }\end{array}$ & 408 & 398 & 97,5 \\
\hline $\begin{array}{l}\text { Técnica de levantamento de re- } \\
\text { cursos asssistenciais dos alunos }\end{array}$ & 398 & 373 & 93,7 \\
\hline $\begin{array}{l}\text { Orientação a aluno com proble- } \\
\text { ma de saúde }\end{array}$ & 396 & 386 & 97,5 \\
\hline $\begin{array}{l}\text { Orientação à família de aluno } \\
\text { com problema de saúde }\end{array}$ & 391 & 376 & 96,2 \\
\hline $\begin{array}{l}\text { Encaminhamento de aluno com } \\
\text { problema de saúde }\end{array}$ & 401 & 391 & 97,5 \\
\hline $\begin{array}{l}\text { Seguimento de caso encaminha- } \\
\text { do }\end{array}$ & 393 & 352 & 89,6 \\
\hline $\begin{array}{l}\text { Registro de dados relativos ao } \\
\text { caso encaminhado }\end{array}$ & 390 & 350 & 89,7 \\
\hline
\end{tabular}

fundamenta as ações de saúde escolar propostas. A Tabela 4 foi construída com base nas associações de respostas, apresentando-se apenas aquelas de frequiência igual ou superior a 5 .

Examinando-se a Tabela 3 nota-se que cerca de $90,0 \%$ dos professores receberam todas as explicações mencionadas. Não obstante, observando-se a Tabela 4 , mostrando as várias formas de respostas associadas, verifica-se que essa proporção é inferior $(74,3 \%)$. Tudo leva a crer que a maior parte dos respondentes recebeu orientação do OAE sobre a técnica da observação de saúde. Parece não ocorrer o mesmo em relação às medidas para solucionar problemas de saúde do escolar, em especial, ao encaminhamento e seguimento de casos. Essa constatação leva a conjeturar-se acerca das respon- sabilidades que o professor se atribuiria face a tais atividades, percepção esta que poderia influir tanto na sua receptividade às orientaçőes, quanto na ênfase com que o OAE as realizaria. Era de conhecimento do professor, de acordo com atos legais ${ }^{4,14}$, que o OAE contava com carga horária e remuneração especialmente destinadas à execução de açðes de saúde. Assim sendo, poder-se-ia perguntar se esse fato influiria na percepção e conduta do professor face a atividades da programação a ele solicitadas.

As Tabelas 5 e 6, mostram os resultados das auto-avaliações do professor a respeito do seu preparo para realizar atividades previstas na programação. Esses resultados, expressos pelo VEM, evidenciam que os professores se consideram apenas razoavelmente preparados para realizar tanto a observação de saúde como a orientação sobre problemas de saúde. Isto leva a supor duas possibilidades - o preparo dos professores pode ter sido insuficiente e/ou eles estão subestimando a própria capacidade, pontos estes que certamente justificariam posterior estudo avaliativo a nivel local.

Nesta linha, Davis e col. ${ }^{3}$ realizaram "survey" com o objetivo de verificar a percepção de professores sobre seu preparo e habilidade em reconhecer e lidar com problemas de saúde dos seus alunos. A amostra foi constituída por 555 professores elementares e "intermediários", do distrito escolar de Kalamazoo, Michigan, aos quais foi aplicado um questionário de 40 ítens, construídos com uma escala de tipo Lickert. O instrumento listava problemas comuns e observáveis de saúde, perguntando-se ao professor quão à vontade se sentiria ao lidar com alunos que os apresentassem. Os autores verificaram que mais da metade dos respondentes $(53,7 \%)$ nunca havia participado de qualquer treinamento ou de evento similar sobre educação em saúde. Além disso, não se sentiam à vontade para lidar com desvios da saúde, preferindo deixá-los a cargo de profissionais de saúde. Mostraram os autores que professores com treinamento insuficiente sentem-se menos à vontade para lidar com distúrbios de saúde do aluno. Esses resultados mostram-se coerentes com aqueles das Tabelas 5 e 6 , do presente trabalho.

Embora a preparação dos professores fosse realizada com base no mesmo conteúdo técnico em todas as regiōes administrativas do Estado, deve-se admitir a existência de possiveis diferenças locais, decorrentes de fatores pessoais e administrativos, referentes tanto ao OAE e professores, quanto à organização escolar. Por essa razão, introduziu-se o município-sede da escola como variável de interesse. Os resultados desses cruzamentos constam das Tabelas 7 e 8 . 
TABELA 4

Explicaçðes recebidas por meio do orientador de ações de assistência ao escolar: formas de associação. Professores da primeira série do primeiro grau de escolas estaduais de 13 munić́pios do Estado de São Paulo, Brasil, 1983

$\mathrm{n}=424$

\begin{tabular}{|c|c|c|c|c|c|c|c|c|c|}
\hline & & \multicolumn{8}{|c|}{ Formas de Associação } \\
\hline \multicolumn{2}{|c|}{ Respondentes } & \multirow{2}{*}{$\begin{array}{l}\text { Técnica } \\
\text { da obser- } \\
\text { vação de } \\
\text { saúde }\end{array}$} & \multirow{2}{*}{$\begin{array}{l}\text { Problemas } \\
\text { de saúde } \\
\text { a serem } \\
\text { observa- } \\
\text { dos }\end{array}$} & \multirow{2}{*}{$\begin{array}{l}\text { Técnica } \\
\text { de levan- } \\
\text { tamento } \\
\text { de recur- } \\
\text { sos assis- } \\
\text { tenciais }\end{array}$} & \multirow{2}{*}{$\begin{array}{l}\text { Orientação } \\
\text { a aluno } \\
\text { com pro- } \\
\text { blema de } \\
\text { saúde }\end{array}$} & \multirow{2}{*}{$\begin{array}{l}\text { Orientação } \\
\text { à família } \\
\text { de aluno } \\
\text { com pro- } \\
\text { blema de } \\
\text { saúde }\end{array}$} & \multirow{2}{*}{$\begin{array}{l}\text { Encaminha- } \\
\text { mento de } \\
\text { aluno com } \\
\text { problema } \\
\text { de saúde }\end{array}$} & \multirow{2}{*}{$\begin{array}{c}\text { Seguimento } \\
\text { de caso } \\
\text { encaminha- } \\
\text { do }\end{array}$} & \multirow{2}{*}{$\begin{array}{c}\text { Registro } \\
\text { de dados } \\
\text { relativos } \\
\text { ao caso } \\
\text { encami- } \\
\text { nhado }\end{array}$} \\
\hline$f$ & $\%$ & & & & & & & & \\
\hline 315 & 74,3 & $\mathrm{X}$ & $\mathrm{x}$ & $\mathrm{X}$ & $\mathrm{X}$ & $\mathrm{X}$ & $X$ & $\mathrm{X}$ & $\mathrm{X}$ \\
\hline 11 & 2,6 & $\mathrm{X}$ & $X$ & $\mathrm{X}$ & $\mathrm{X}$ & $\mathrm{X}$ & & & \\
\hline 10 & 2,4 & $\mathrm{X}$ & & & & & & & \\
\hline 8 & 1,9 & & $\mathrm{X}$ & & & & & & \\
\hline 8 & 1,9 & $\mathrm{X}$ & $\mathrm{X}$ & $\mathrm{X}$ & $\mathrm{X}$ & $\mathrm{X}$ & $\mathrm{X}$ & $\mathrm{X}$ & \\
\hline 7 & 1,6 & $\mathrm{X}$ & $\mathrm{X}$ & $\mathrm{X}$ & $\mathrm{X}$ & $\mathrm{X}$ & $\mathrm{X}$ & & $\mathrm{X}$ \\
\hline 5 & 1,2 & $\mathrm{X}$ & $\mathrm{X}$ & & & & & & \\
\hline 5 & 1,2 & $\mathrm{X}$ & $\mathrm{X}$ & & $\mathrm{X}$ & $\mathrm{X}$ & $\mathrm{X}$ & $\mathbf{X}$ & $\mathrm{X}$ \\
\hline $12^{*}$ & 2,8 & 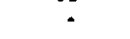 & 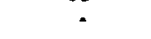 & & 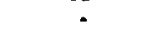 & . & $\because$ & . & $\because$ \\
\hline $18^{* *}$ & 4,2 & & & & & & & & \\
\hline $25 * * *$ & 5,9 & & & & & & & & \\
\hline
\end{tabular}

* 4 grupos de 3 respondentes

** 9 grupos de 2 respondentes

*** 25 grupos de 1 respondente

Cada grupo apresentou uma forma particular de associação.

Dados omitidos em razão da multiplicidade de informações.

\section{TABELA 5}

Auto-avaliação do preparo para realizar a observação do estado de saúde dos alunos. Professores da prımeira série do primeiro grau de escolas estaduais de 13 municípios do Estado de São Paulo, Brasil, 1983

\begin{tabular}{lrr} 
& & $\mathrm{n}=530$ \\
\hline $\begin{array}{l}\text { Auto-avaliação do preparo para } \\
\text { realizar observação de saúde }\end{array}$ & $f$ & $\%$ \\
\hline (-) Considera-se preparado & 527 & 99,4 \\
(0) Considera-se não preparado & 3 & 0,6 \\
\hline Considera-se: & & \\
(5) muito bem preparado & 61 & 11,6 \\
(4) bem preparado & 163 & 30,9 \\
(3) mais ou menos preparado & 271 & 51,5 \\
(2) mal preparado & 26 & 4,9 \\
(1) muito mal preparado & 6 & 1,1 \\
\hline Valor escalar médio* & $3,4(69)$ \\
\hline
\end{tabular}

* Calculado a partir dos números entre parênteses. Limites das escalas: 0 e 5, 0 e 100.

De acordo com a Tabela 7, a orientação dada por intermédio dos OAEs atingiu todos os municípios, em maior ou menor proporção. As variaçð̃es observadas, apresentadas em ordem de-
TABELA 6

Auto-avaliação do preparo para orientar alunos sobre problemas de saúde mais comuns. Professores da primeira sérje do primeiro grau de escolas estaduais de 13 municípios do Estado de São Paulo, Brasil, 1983

\begin{tabular}{lrr} 
& & $\mathrm{n}=529$ \\
\hline $\begin{array}{c}\text { Auto-avałiação do preparo para } \\
\text { orientar sobre problemas de saúde }\end{array}$ & $\mathrm{f}$ & $\%$ \\
\hline (-) Considera-se preparado & 514 & 97,2 \\
(0) Considera-se não preparado & 15 & 2,8 \\
\hline
\end{tabular}

Considera-se preparado para

orientar sobre:

$\begin{array}{lrr}\text { (4) todos os problemas } & 76 & 14,8 \\ \text { (3) quase todos os problemas } & 169 & 32,9 \\ \text { (2) a média dos problemas } & 211 & 41,0 \\ \text { (1) poucos problemas } & 58 & 11,3\end{array}$

Valor escalar médio* 2,4 (61)

* Calculado a partir dos números entre parênteses. Limites das escalas: 0 e 4, 0 e 100 .

crescente, situam-se na faixa de $70 \%$ a $100 \%$, com exceção de São Roque, onde se verifica o valor mais reduzido $(54,5 \%)$, fato que mereceria investigação "in loco". Constatam-se, as- 


\section{TABELA 7}

Recebimento de explicaçōes ministradas pelo orientador de ações de assistência ao escolar sobre a aplicação do manual "Observação de Saúde do Escolar", segundo município. Professores da primeira série do primeiro grau de escolas estaduais de 13 municípios do Estado de São Paulo, Brasil, 1983.

\begin{tabular}{|c|c|}
\hline Município & Receberam Explicações \\
\hline $\begin{array}{l}\text { Echaporã } \\
\qquad(n=5)\end{array}$ & 100,0 \\
\hline $\begin{array}{l}\text { Lençóis Paulista } \\
(\mathrm{n}=11)\end{array}$ & 100,0 \\
\hline $\begin{array}{l}\text { Araçatuba } \\
\qquad(\mathrm{n}=78)\end{array}$ & 97,4 \\
\hline $\begin{array}{l}\text { Presidente Venceslau } \\
\qquad(\mathrm{n}=45)\end{array}$ & 93,3 \\
\hline $\begin{array}{l}\text { Catanduva } \\
\qquad(n=42)\end{array}$ & 88,1 \\
\hline $\begin{array}{l}\text { Franca } \\
\qquad(\mathrm{n}=86)\end{array}$ & 80,2 \\
\hline $\begin{array}{l}\text { Registro } \\
\qquad(n=30)\end{array}$ & 80,0 \\
\hline $\begin{array}{c}\text { Sta. Bárbara D'Oeste } \\
(n=46)\end{array}$ & 78,3 \\
\hline $\begin{array}{l}\text { Caçapava } \\
\qquad(n=9)\end{array}$ & 77,8 \\
\hline${ }^{\text {Arujá }}(n=16)$ & 75,0 \\
\hline $\begin{array}{l}\text { Cotia } \\
(n=64)\end{array}$ & 73,4 \\
\hline $\begin{array}{l}\text { Praia Grande } \\
\qquad(\Omega=60)\end{array}$ & 71,7 \\
\hline $\begin{array}{l}\text { Sāo Roque } \\
\qquad(\mathrm{n}=33)\end{array}$ & 54,5 \\
\hline
\end{tabular}

sim, diferenças na preparação dos professores para utilizar o manual, conforme o município-sede da escola.

Os valores escalares médios da Tabela 8 , ordenados segundo sua magnitude, fornecem uma idéia aproximada da intensidade com que os professores das diversas localidades auto-avaliam o conhecimento do manual "Observação de Saúde do Escolar"'.

Como se observa, apenas parcela reduzida de respondentes conhece muito bem o seu conteúdo, qualquer que seja o município focalizado. As discrepâncias notadas levam a supor que o manual não estaria sendo distribuído de igual maneira em todas as localidades. Essa suposição parece confirmar-se nos resultados constantes na Figura, onde se evidencia que 36,1\% dos professores não dispunham do referido material. Conforme informações obtidas no estudo exploratório, poder-se-ia presumir que a insuficiente quantidade de manuais levaria o OAE a mimeografar parceladamente seu conteúdo, à medida da transmissão das orienta- ções. Isto explicaria, em parte, os valores percentuais referentes aos diversos niveis de conhecimento, observados nos vários municípios.

Por outro lado, as variaçoes entre os VEMs reforçam a idéia da heterogeneidade de preparo dos professores sobre o conteúdo do citado manual, nas localidades em estudo.

A fim de se obter melhor informação sobre o preparo dos professores, procedeu-se ao cruzamento de variáveis referentes à auto-avaliação, apresentado na Tabela 9.

Acredita-se necessário justificar a utilização da variável "auto-avaliação de conhecimentos", desde que seria desejável se lançar mão de medida objetiva de conhecimentos dos professores sobre o conteúdo do manual. Esse procedimento não pôde ser adotado em vísta da impraticabilidade de sua viabilização. Aceitou-se, portanto, a auto-avaliação como um indicador possível da medida objetiva. Conhecidos os resultados, ademais, pretendia-se verificar se essa suposição teria alguma conseqüência.

Os resultados parecem confirmar os pressupostos iniciais, evidenciando que essa variável estaria cumprindo a função discriminatória esperada. Como os resultados observados dirigem-se sistematicamente para um mesmo sentido, isto deve ocorrer porque seu mecanismo de ação provavelmente coincide com a medida objetiva do conhecimento.

$O$ " $T$ " indica associação positiva entre a auto-avaliação de conhecimentos sobre o manual e auto-avaliação do preparo para realizar a observação de saúde. Esse resultado vem ao encontro das expectativas, levando-se em conta que, comumente, existe correspondência entre os dois fatos, ou seja, o conteúdo do manual deve auxiliar o professor na observação do estado de saúde de seus alunos. $E$, parece que os dados confirmam essa versão.

Tentando obter maior esclarecimento, procurou-se verificar a existência de relação entre 0 fato de o professor ter sido orientado sobre a aplicação do manual e a auto-avaliação do preparo para realizar a observação de saúde (Tabela 10). Os resultados expressos pelos VEMs parecem indicar relação entre as duas variáveis da Tabela 10, como esperado.

Considerando-se que uma das atribuições do OAE consistia em transmitir a orientação sobre a técnica da observação de saúde aos seus colegas de unidade escolar, tudo leva a crer que essa tarefa foi razoavelmente cumprida. As diferenças observadas entre as categorias podem ser atribuídas a fatores pessoais - tanto do OAE quanto do professor - a fatores situacionais e/ou ao fato de dispor do referido manual ${ }^{9}$, conforme explicado anteriormente. 
TABELA 8

Auto-avaliação de conhecimentos sobre o manual "Observação de Saúde do Escolar", segundo o município*. Professores da primeira série do primeiro grau de escolas estaduais de 13 municípios do Estado de São Paulo, Brasil, 1983.

\begin{tabular}{|c|c|c|c|c|c|c|c|}
\hline \multirow{2}{*}{$\begin{array}{c}\text { Municí- } \\
\text { pio }\end{array}$} & \multicolumn{5}{|c|}{$\begin{array}{c}\text { Auto-avaliação de conhecimentos sobre } \\
\text { o manual }\end{array}$} & \multirow{2}{*}{\multicolumn{2}{|c|}{$\begin{array}{c}\text { Valor } \\
\text { Escalar } \\
\text { Médio** }\end{array}$}} \\
\hline & \multirow{2}{*}{$\begin{array}{c}\text { (4) Conhe- } \\
\text { ce muito } \\
\text { bem }\end{array}$} & \multirow{2}{*}{ 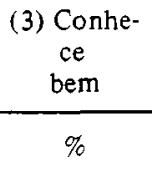 } & \multirow{2}{*}{$\begin{array}{l}\text { (2) Conhe- } \\
\text { ce mais } \\
\text { ou menos } \\
\%\end{array}$} & \multirow{2}{*}{$\begin{array}{c}\text { (1) Conhe- } \\
\begin{array}{c}\text { ce } \\
\mathrm{mal}\end{array} \\
\%\end{array}$} & \multirow{2}{*}{$\begin{array}{c}\begin{array}{c}\text { (0) Conhe- } \\
\text { ce muito } \\
\text { mal }\end{array} \\
\%\end{array}$} & & \\
\hline & & & & & & $\begin{array}{l}(0 \mathrm{e} \\
4) * * *\end{array}$ & $\begin{array}{c}(0 \mathrm{e} \\
100)^{* * *}\end{array}$ \\
\hline $\begin{array}{r}\text { Catanduva } \\
(\mathrm{n}=36)\end{array}$ & 44,4 & 27,8 & 27,8 & - & - & 3,2 & 79 \\
\hline Lençóis & & & & & & & \\
\hline $\begin{array}{l}\text { Paulista } \\
\qquad(n=11)\end{array}$ & 36,4 & 36,4 & 27,2 & - & - & 3,1 & 77 \\
\hline $\begin{array}{l}\text { Arujá } \\
\qquad(\mathrm{n}=4)\end{array}$ & 25,0 & 50,0 & 25,0 & - & - & 3,0 & 75 \\
\hline $\begin{array}{l}\text { Franca } \\
\qquad(\mathrm{n}=30)\end{array}$ & 13,3 & 60,0 & 26,7 & - & - & 2,9 & 72 \\
\hline $\begin{array}{l}\text { São Roque } \\
\qquad(\mathrm{n}=15)\end{array}$ & 13,3 & 46,7 & 40,0 & - & - & 2,7 & 68 \\
\hline $\begin{array}{l}\text { Araçatuba } \\
(\mathrm{n}=57)\end{array}$ & 15,8 & 29,8 & 52,6 & 1,8 & - & 2,6 & 65 \\
\hline $\begin{array}{l}\text { Praia Grande } \\
\quad(n=45)\end{array}$ & 6,7 & 44,4 & 46,7 & 2,2 & - & 2,6 & 64 \\
\hline Presidente & & & & & & & \\
\hline $\begin{array}{l}\text { Venceslau } \\
(\mathrm{n}=32)\end{array}$ & 9,4 & 31,3 & 56,2 & 3,1 & - & 2,5 & 62 \\
\hline $\begin{array}{l}\text { Registro } \\
\qquad(\mathrm{n}=21)\end{array}$ & 9,5 & 28,6 & 57,1 & 4,8 & - & 2,4 & 61 \\
\hline Sta. Bárbara & & & & & & & \\
\hline $\begin{array}{l}\text { D'Oeste } \\
(\mathrm{n}=35)\end{array}$ & 5,7 & 34,3 & 54,3 & 5,7 & - & 2,4 & 60 \\
\hline $\begin{array}{l}\text { Cotia } \\
(n=44)\end{array}$ & 18,2 & 34,1 & 43,1 & 2,3 & 2,3 & 2,2 & 55 \\
\hline $\begin{array}{l}\text { Caçapava } \\
(\mathrm{n}=6)\end{array}$ & - & 50,0 & 33,3 & - & 16,7 & 2,2 & 54 \\
\hline
\end{tabular}

* O município de Echaporã não foi incluído devido ao não recebimento ou leitura do manual pelos professores.

** Calculado a partir dos números entre parênteses.

*** Limites da escala.

TABELA 9

Auto-avaliação do preparo para realizar a observação de saúde, segundo a auto-avaliação de conhecimentos sobre 0 manual "Observação de Saúde do Escolar". Professores da primeira série do primeiro grau de escolas estaduais de 13 municípios do Estado de São Paulo, Brasil, 1983.

\begin{tabular}{|c|c|c|c|c|}
\hline \multirow{2}{*}{$\begin{array}{l}\text { Auto-avaliação do } \\
\text { preparo para } \\
\text { observação de saúde }\end{array}$} & \multicolumn{4}{|c|}{ Auto-avaliação de conhecimentos sobre o manual } \\
\hline & $\begin{array}{l}\text { Conhece } \\
\text { muito bem }\end{array}$ & $\begin{array}{l}\text { Conhece } \\
\text { bem }\end{array}$ & $\begin{array}{l}\text { Conhece } \\
\text { mais ou menos }\end{array}$ & $\begin{array}{c}\text { Conhece } \\
\text { mal ou muito mal }\end{array}$ \\
\hline & $\mathrm{n}=54$ & $\mathrm{n}=123$ & $n=149$ & $\mathrm{n}=9$ \\
\hline & $\%$ & $\%$ & $\%$ & $\%$ \\
\hline (5) Muito bem preparado & 48,1 & 17,1 & 4,7 & - \\
\hline (4) Bem preparado & 31,5 & 51,2 & 26,2 & 11,1 \\
\hline (3) Mais ou menos preparado & 20,4 & 30,9 & 65,1 & 44,5 \\
\hline (2) Mal preparado & - & 0,8 & 2,7 & 22,2 \\
\hline (1) Muito mal preparado & - & - & - & 22,2 \\
\hline (0) Sem nenhum preparo & - & - & 1,3 & - \\
\hline $\begin{array}{l}\text { Valor escalar médio* } \\
\mathrm{T}^{* *}=0,36\end{array}$ & $4,3(86)$ & $3,8(77)$ & $3,3(66)$ & $2,4(49)$ \\
\hline
\end{tabular}

* Calculado a partir dos números entre parênteses. Limites das escalas: 0 e $5 ; 0$ e 100.

** Valor original de "Tau C" calculado a partir de tabela completa, onde as categorias "conhece mal" e "conhece muito mal" eram distintas. 


\section{TABELA 10}

Auto-avaliação do preparo para realizar a observação da saúde dos alunos, segundo o recebimento de explicações do orientador de açōes de assistência ao escolar sobre a aplicação do manual "Observação de Saúde do Escolar". Professores da primeira série do primeiro grau de escolas estaduais de 13 municípios do Estado de São Paulo, Brasil, 1983

\begin{tabular}{lcc}
\hline & \multicolumn{2}{c}{$\begin{array}{c}\text { Recebimento de } \\
\text { explicações }\end{array}$} \\
\cline { 2 - 3 } $\begin{array}{c}\text { Auto-avaliação do preparo } \begin{array}{c}\text { para realizar a } \\
\text { observação de saúde }\end{array} \\
\end{array}$ & $\mathrm{n}=425$ & $\mathrm{n}=98$ \\
\hline & $\%$ & $\%$ \\
(5) Muito bem preparado & 12,9 & 6,1 \\
(4) Bem preparado & 34,1 & 15,3 \\
(3) Mais ou menos preparado & 48,5 & 63,3 \\
(2) Mal preparado & 2,8 & 13,3 \\
(1) Muito mal preparado & 1,2 & 1,0 \\
(0) Sem nenhum preparo & 0,5 & 1,0 \\
\hline \multicolumn{1}{c}{ Valor escalar médio* } & $3,5(71)$ & $3,1(62)$ \\
\hline
\end{tabular}

* Calculado a partir dos números entre parênteses. Limites das escalas: 0 e $5 ; 0$ e 100 .

\section{CONCLUSÕES}

1. A maioria dos professores recebeu preparação para desempenho de atividades que visam à identirîicação e atendimento de escolares com problemas de saúde.

2. A variação intermunicipal referente à cobertura na orientação dada pelos OAEs ocorreu dentro de limites aceitáveis.

3. Dentre as explicações transmitidas pelos OAEs, aos professores, predominou a da técnica da observação de saúde em relação às demais, quanto à cobertura de orientação.

4. A possivel relação entre o fato de o professor ter recebido explicações do OAE sobre a aplicação do manual "Observação de Saúde do Escolar" e o melhor grau na auto-ava- liação do preparo para realizar a observação de saúde indica, provavelmente, eficácia do trabalho do OAE na escola.

5. O fato de receber o manual "Observação de Saúde do Escolar" parece influir positivamente, seja na proporção de docentes que o lêem, seja na extensão com que o material é lido.

6. A associação positiva entre a auto-avaliação de conhecimentos sobre o manual e a auto-avaliação do preparo para realizar a observação de saúde indica que o referido material estaria auxiliando o professor a desempenhar essa atividade.

\section{RECOMENDAÇÕES}

Tendo em vista os resultados e as conclusðes do presente estudo, recomenda-se:

1. Continuidade e aperfeiçoamento do sistema de orientação a professores, visando ampliar seus conhecimentos e conseqüente compreensão a respeito do papel que desempenham em ações de saúde na escola.

2. Distribuição do manual "Observação de Saúde do Escolar" a todos os professores abrangidos pela programação.

3. Re-introdução da função de OAE na rede estadual de ensino, ampliando a carga horária destinada a essa tarefa.

4. Apoio das autoridades de ensino e de saúde dos diversos níveis ao trabalho de preparo de docentes para ações de detecção e atendimento de desvios de saúde do escolar.

5. Reformulação do currículo do curso de formação do magistério, melhor preparando o futuro professor para agir face a necessidades, interesses e problemas de saúde do escolar. 
TEMPORINI, E.R. [Teachers' perception of a school children's health training program for teachers under the S.Paulo State (Brazil) education system]. Rev. Saúde públ., S. Paulo, 22:411-21, 1988.

ABSTRACT: Its is presented a study on the teachers' perception of a training program directed to the identification and care of schoolchildren with health problems. The intention being to offer data useful for the planning of teachers' training programs for governmental sectors concerned with this subject. The population comprised 532 first-grade teachers of public elementary schools located in thirteen counties of the S.Paulo State (Brazil) in wich the "Integrated System of Medical Care for Schoolchildren" had first been implanted. A questionnaire was used for data collection. Results showed that $74.3 \%$ of the teachers considered themselves to be trained in health observation techniques and in health problem-solving measures. The orientation provided by the School Health Coordinator (SHC) covered from 70 to $100 \%$ of teachers working in the geographical areas mentioned. The relationship shown between the orientation provided by the SHC and a better performance in terms of the teacher's self-evaluations regarding his/her preparation is a fact that probably indicates the efficacy of the work of the SHCs. An increase in these actions at the state public school network level, enlarging the teacher's knowledge and understanding regarding his/her participation in school health programs is recommended.

UNITERMS: School health. School health services. Inservice training. Teacher.

\section{REFERÊNCIAS BIBLIOGRÁFICAS}

1. ANDERSON, C.L.\& CRESWELL, W.H. School health practice. $6^{\text {th }}$ ed. St. Louis, C.V. Mosby, 1976.

2. CANDEIAS, N.M.F. Ensino da saúde: interesses na área de saúde de escolares adolescentes. Cad. Pesq., S. Paulo, (50):40-52, 1984.

3. DAVIS, C. et al. Health concerns and teacher training of selected elementary teachers in Michigan. J. Sch. Hlth, 55:151-3, 1985.

4. DECRETO n: 15.023, de 6 de maio de 1980: dispóe sobre a designação de docentes para atuar na assistência ao escolar. Diário Oficial do Estado, S. Paulo, 7 maio 1980. p.3

5. GATTI, B.A. et al. Um estudo sobre os cursos de formação de professores a nivel de $2^{\circ}$ grau (antigos cursos normais). Cad. Pesq., S. Paulo, (20):15-37, 1977.

6. GRIFFITH, B.B. \& WICKER, P.H. Teacher-observer of student health problem. J. Sch. Hlth, 51:428-32, 1981.

7. JOINT WHO/UNESCO EXPERT COMMITTEE ON TEACHER PREPARATION FOR HEALTH EDUCATION, Geneva, 1959. Report. Geneva, 1960. (WHO - Technical Report Series, 193).

8. MARCON̈DES, R.S. O preparo da professora primária em educação sanitária. São Paulo, 1968. [Tese de Livre-Docência - Faculdade de Saúde Pública da USP].

9. MENDES, D. \& TEMPORINI, E.R. Introdução do orientador de açōes de assistência ao escolar no campo da educação em saúde na escola. [Apresentado ao II Congresso Paulista de Saúde Pública/I Congresso Nacional da ABRASCO, São Paulo, 1983].

10. MENDES, D. et al. Observação de saúde do escolar: manual para o professor. São Paulo, Secretaria de Estado da Educação, 1978.

11. NEMIR, A. The school health program - a textbook for teachers. $3^{\text {rd }}$ ed. Plilladelphia, W.B. Saunders, 1970.

12. OBERTEUFFER, D. et al. School health education. $5^{\text {th }}$ ed. New York, Harper \& Row Publ., 1972.

13. RITTER, A.M. Using a teacher's health observation form to evaluate school child health. J. Sch. H/th, 46:235-7, 1976.

14. SECRETARIA DE ESTADO DA EDUCAÇÃO. Resolução S.E. n: 96: regulamenta a designação de docentes para atuar na área de assistência ao escolar. Diário Oficial do Estado, S. Paulo, 24 jun. 1980. p.13

15. SECRETARIA DE ESTADO DA EDUCAÇÃO. Departamento de Assistência ao Escolar. Divisão de Estudos, Normas e Programas em Assistência Médica. Equipe Técnica - Educação em Saúde. Projeto: orientaçăo sobre necessidades e problemas de saúde do escolar e açōes de saúde na escola. São Paulo, 1980. [Mimeografado].

16. SECRETARIA DE ESTADO DA EDUCAÇĀO. Departamento de Assistência ao Escolar. Divisão de Estudos, Normas e Programas em Assistência Médica. Equipe Técnica - Educação em Saúde.'Projeto: treinamento de coordenadores de saúde. Såo Paulo, 1978. [Mimeografado].

17. SECRETARIA DE ESTADO DA EDUCAÇĀO. Serviço de Saúde Escolar. Seção de Educação em Saúde. Aspectos do ensino de biologia aplicada à educação e saúde pública nos cursos colegial normal das escolas oficiais da Secretaria da Educação do Estado de São Paulo. São Paulo, 1975. [Mimeografado].

18. SIEGEL, S. Estatística não-paramétrica. São Paulo, McGraw-Hill do Brasil, 1975:

19. SILVER, G.A. Redefining school health services: comprehensive child health care as framework. $J$. Sch. Hlth, 51:157-62, 1981.

20. SISTEMA Integrado de Atendimento Médico ao Escolar (SIAME). São Paulo, Secretaria de Estado da Educação, 1977? [Mimeografado].

21. SOUZA, C.F.M. de et al. Avaliação das condições de saúde da população estudantil. In: Encontro de Secretários de Educação e Presidentes de Conselhos de Educação, com a participação dos Secretários de Saúde, 10, Brasilia, 1976. Anais. Brasília, Departamento de Documentação e Divulgação. MEC, 1977. p. 25-52. 
22. TEMPORINI, E.R. et al. Validade da aferição da acuidade visual realizada pelo professor em escolares de 1! a 4? série do primeiro grau de uma escola pública do município de Såo Paulo, Brasil. Rev. Saúde públ., S. Paulo, 11:229-37, 1977.

23. TURNER, C. et al. School health and health education. $6^{\text {th }}$ ed. Saint Louis, C.V. Mosby, 1970.

24. WHEATLEY, G.M. \& HALLOCK, G.T. Health observation of school children. New York, MacGraw-Hill, 1951.
25. WORLD HEALTH ORGANIZATION. Regional Office for Europe. Problems of children of school age (5-9 years); report on a Working Group, Copenhagen, 1975. Copenhagen, 1976.

Recebido para publicaçāo em 30/10/1987 Reapresentado em $5 / 5 / 1988$

Aprovado para publicação em 10/5/1988 